\title{
An Alternative Strategy For Building Sales Of Computers: Generic Advertising
}

\author{
Min Lu, (E-mail: lu@rmu.edu), Robert Morris University \\ Steven Thompson, (E-mail: sthomps3@richmond.edu), University of Richmond \\ Yanbin Tu, (E-mail: tu@rmu.edu), Robert Morris University
}

\begin{abstract}
Frequent upgrading and aggressive price-cutting have become standard practice in the computer sector. While necessitated in part by declining production costs and a highly competitive market, these strategies have also served to make computers more affordable, growing the size of the overall market. Recently downturns in the sales of computers motivate us to examine the impact of these strategies on overall sales growth. We find evidence to suggest that excessive upgrading and overly aggressive price-cutting can be detrimental to overall sales growth. We also find that the computer sector exhibits characteristics that suggest that generic advertising would be an effective mechanism to enhance overall sales growth.
\end{abstract}

Keywords: Computer Sales, Computer Quality, Generic Advertising, Vector-ECM, Co-integration Analysis

\section{Introduction}

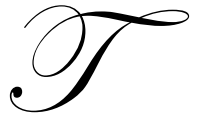

hroughout the 1990's the total sales for the computers grew rapidly. During this time period sales of computers (and associated peripherals) grew at annual rates as high as $20 \%$ while packaged software sales grew at an average rate of $12 \%$. This growth was associated with the frequent release of new versions of existing products, or entire replacement products, and rapidly falling prices. With less expensive products that offered improved functionality large numbers of new buyers entered the market and repeat buyers returned to purchase again.

As a result, frequent product upgrading and aggressive price cuts become the dominant strategy used by computer vendors to increase sales. Upgrading and price reduction have become so entrenched in the industry that, to our knowledge, no research has been conducted to investigate how these strategies actually impact the growth of overall sales. The sales of computers have declined in recent years and have been slow to rebound. For computers, while the number of units shipped grew, the dollar value of shipments fell 9.8\% in 2002 and an additional 1.8\% in 2003 (http://money.cnn.com/2003/03/13/technology/idc/). According to the Software and Information Industry Association (SIIA), total sales of packaged software in 2003 fell 3\% from 2002 levels. With the contraction in the overall market, companies have become more competitive in their efforts to attract sales. In addition to brand advertising initiatives, vendors have engaged in even more aggressive price cutting and have brought new and/or improved products to market to try to jump-start sales.

The troubles plaguing companies in the computer sector are obviously partly due to the 2000-2001 global economic recession and the less than spectacular recovery. While the problem is clearly multifaceted (other explanations for poor sales include software piracy, "re-furbished" computers, financial and geo-political uncertainty, residual aversion from the spending sprees of the 1990's, lack of a new "killer app" to act as a sales catalyst, and businesses waiting on further price declinations before purchasing), the focus of this paper is on the impact of frequent upgrading and price reduction strategies on overall sales growth. The intuitive rationale for this focus is that these actions, when performed to excess, can serve to encourage buyers to delay purchases. Given the poor growth of sales, an investigation of the factors that drive sales, and an analysis of strategies that should prove effective in increasing sales, is warranted. 
This paper has two objectives. First, we seek to evaluate the impact of frequent upgrading and aggressive price promotion on total sales. While such strategies are likely to result in at least transient gains for the individual company, we are concerned with the impact of these strategies on the market as a whole. Second, we seek to determine whether the computer (including packaged software) sector can benefit from generic advertising. The goal of generic advertising is to increase the demand for a product, or class of products, without impacting the market share of any of the companies in the market. Recent research, presented in the next section, provides strong theoretical and empirical insights into the conditions that, when present, suggest that generic advertising initiatives can prove fruitful. We will use this existing research to determine whether the market for computers exhibits characteristics such that generic advertising campaigns are worthwhile strategies.

In order to gain an understanding of the impact of price promotions and frequent upgrading on industry sales we examine the "quality" and price of computers (via index values) as well as total expenditure on computers. We then investigate how these factors influence computer sales. The economic rationale behind the selection of these factors is that the sales of a commodity are determined by both the commodity's attributes and the consumers' attributes. In this case, the commodity's attributes are price and quality, and the consumer's attributes are aggregated in expenditure.

As we are concerned with sales for the entire sector, we use the aggregate sales of computers in the United States from January 1992 to February 2002. We use cointegration analysis and a Vector Error Correction Model (VECM) to examine the long-term and short-term relationships among quality, price, total computer sales, and expenditure. The key finding in the paper is that the quality/price ratio is negatively related to computer sales. This suggests that when the quality/price ratio becomes larger (which means the "quality" becomes cheaper), the contribution of this "cheapness" to total computer sales is negative. In addition, we find that an increase in the share of expenditure allocated to technology goods is the primary driver of increases in computer sales. While the latter finding seems intuitive, it has significant practical implications when taken in combination with our key finding.

Specifically, these findings imply that the demand for computers with respect to price is inelastic. The industry implications are that rapid upgrading of these products is not an effective strategy and the premise that drastically lowering prices will promote long-term sales is not valid. Moreover, we find that sales of computers have a low adjusting speed with respect to the convergence of short-run deviations toward a long-run equilibrium. The implication is that price-based sales promotion tactics for enhancing computer sales will require a long time to take effect. We show that while short-term gains may be realized the strategy is ultimately self-defeating. We propose that since (a) the main driver of growth for computers sales is an increase in the share of expenditure allocated to technology products and (b) a significant portion of the market remains "untapped" (in the sense that most forecasts of future growth potential are very positive), that generic advertising strategies are likely to yield benefits in this sector. However, since generic advertising can increase the total size of the market but also potentially change market share, care should be taken when developing these advertisements.

The rest of the paper is organized as follows: Section 2 contains a review of relevant literature. We propose our research hypotheses in Section 3. Section 4 describes the data set and introduces the stationary tests, while Section 5 provides the results of the cointegration analysis and Vector Error Correction model. The results, and the implications, are discussed in Section 6 and conclusions, limitations, and future research are summarized in Section 7.

\section{Literature Review}

In this section we address relevant literature in the areas of demand models that incorporate quality and price, quality-based pricing strategies, quality-adjusted prices and generic advertising.

\subsection{Quality, Price, And Demand}

Scholars in marketing, psychology, and economics have conducted extensive research into the relationships among quality, price, and demand. For the most part, existing literature investigates the relationship between price 
and quality in the context of consumer behavior. Researchers have demonstrated that the likelihood function of buying a product can be written as a function of the difference between quality and price, i.e. (Quality -Price) (Krantz, Luce, Suppes, and Tversky 1971). They also show an alternative to the subtractive model, the ratio model, where the likelihood function is the function of the ratio of quality and price, i.e. (Quality/Price) (Krantz et al. 1971).

Subsequent experimental studies show that a ratio model cannot represent the effects of price and quality information, but a subtractive model can (Hagerty 1978). On the other hand, the author points out that the subtractive model may be converted into the ratio model, as $e^{(\text {Quality-Price })}=e^{\text {Quality }} / e^{\text {Price }}$, so with a minor transformation the ratio model is valid. In these models quality is defined as an aggregation of product attributes and that price can be defined as simply another product attribute (Hagerty 1978). Although the influence of increasing price will be the opposite of increasing the value of the other attributes, and overall, higher price will correspond with lower evaluation. Further research suggests an additive relationship between price and quality, which helps to estimate a price-quality tradeoff coefficient from a small set of data (Levin and Johnson 1984). Additional research into the effect of price and quality on demand suggests that, in the context of a monopoly, quality can be used as a tool to increase revenue and influence market behavior (see Cowling and Cubbin 1971 and Cubbin 1975).

Research has also been conducted with the objective of deriving pricing strategies. An analysis of versioning information goods (such as software), found that different versions of software imply different prices and different levels of quality (Varian 1997). In addition, by setting price and quality (Price/Quality) appropriately, consumers will self-select into high- and low-willingness-to-pay groups (Varian 1997). Further research supports the proposition that under imperfect information prices can serve as a signal of quality (Wolinsky 1983). Under these conditions, the product "mark-up", i.e. price - marginal cost, is a function of how much information is available to the consumer.

In research in the area of quality-adjusted prices for durable goods, customers are seen as buying units of quality rather than the product itself. The general trend is that customers get a much better value when they wait to purchase a new generation of the product as opposed to buying the existing product version (Fishman and Rob 2002). This trend has been observed across a number of industries and product classes including mainframe computers (Chow 1967, and Greenstein 1994), minicomputers (Berndt and Griliches 1993, and Gordon 1990), and software packages (Gandal 1994).

\subsection{Generic Advertising}

The goal of generic advertising is to increase primary demand by attracting new customers, increasing per capita consumption, and lengthening the product life cycle (Friedman and Friedman 1976). In theory, generic advertising can increase the demand for a product without impacting the market share of any of the companies in the market (Chakravarti and Janiszewski 2004). This is because generic advertising is designed to enhance category beliefs, increase across category differentiation, and reduce the advertised category's price elasticity (Chakravarti and Janiszewski 2004). In the agricultural sector research that controls for the impact of demographic, social, and environmental trends suggest that generic advertising is effective at achieving its sale goals (Forker and Ward 1993, and Williams 1999). While common in the commodity markets, generic advertising has already been used to promote new product categories in the technology sector, namely satellite radio, digital televisions, and recordable DVD formats (Bass, Krishnamoorthy, Prasad, and Sethi 2004).

In some cases generic advertising campaigns are implemented by individual companies, but in cases where the generic campaign is due to a strategic alliance between firms or the creation of an industry consortium, the goal is co-opetition. That is, first cooperate to grow the size of the market then compete in order to obtain as much market share as possible (Brandenburger and Nolebuff 1997).

Generic advertising has been successfully implemented in a number of circumstances, including "Got milk?" by the National Dairy Council, "Plastics make it possible" by the American Plastics Council, "Gotcha!" by Norelco, "The Incredible Edible Egg" by The American Egg Board, "The Fabric of Our Lives" by The Cotton Board, "Pork: The Other White Meat" by The National Pork Board, and of course the iconic singing California 
Raisins by the California Raisin Advisory Board. Despite the success, concerns remain over whether generic advertising can truly increase overall demand without impacting market share. Experimental studies have shown that generic advertising can increase or decrease product differentiation, thereby impacting market share, depending on which attributes are depicted in the generic advertisement (Chakravarti and Janiszewski 2004). On the other hand, generic advertising can expand the size of the market without impacting market share if the advertisement focuses on the benefits of ownership or consumption rather than any particular product attribute (Chakravarti and Janiszewski 2004).

Research characterizing the optimal advertising policies (in terms of the allocation of funds to generic and brand-specific advertising) in the presence of competitive effects has been addressed using a static model (Krishnamurthy 2000 and 2001) as well as a dynamic competitive model (Bass et al. 2004). Of interest here is that the latter finds that generic advertising is most advantageous when there exists a significant amount of untapped market demand (i.e. there is good growth potential).

\section{Research Hypotheses}

Quality upgrading is used to describe the practice by which existing products are enhanced with more functionality and new features. For example, companies like Intel frequently brings new CPU's with enhanced capabilities to the market. In this study, the increase of computer quality mainly refers to "sequential" upgrading of computer components such as CPU, RAM, hard drive and bundled built-in software etc.

There are three primary reasons why an IT vendor would be motivated to release an upgrade of a product. First, most IT products can be categorized as durable goods. Without any new functionality it is not possible to entice the customer to make a repeat purchase. Therefore the strategy of "planned obsolescence" (Bulow, 1982), whereby the current product generation is made "out-of-date" by the release of new upgraded product, helps vendors of computers extract more surplus from existing consumers. A second factor that motivates upgrading is that market demand evolves and consumers need additional product functions. Through an upgrade, the vendor can not only better serve the existing market, but also attract potential buyers and stimulate new demand (Ng, 2001). Third, technological improvements result in faster CPUs, larger memories and hard disks, all of which offer more flexibility for a new generation of IT products.

However, frequent upgrading may also have the unintended consequence of spurring a more complex decision-making process on the part of the consumer. That is, the consumer may do more than simply look at the difference between valuation and price and make the appropriate consumer surplus maximizing decision. The consumer may also take into account the fact that, in the very near future, an upgraded product will be released that provides greater quality for the price. The presence, in the near future, of a product with a lower quality-adjusted price may cause the consumer to lower his valuation of a given product in anticipation of lower future qualityadjusted prices. The result is that the consumer may make the decision to purchase based on an "adjusted" consumer surplus that takes into account anticipated future lower quality-adjusted prices and the "cost of waiting". For some consumers making a decision based on an adjusted consumer surplus will be enough to choose to leapfrog the new version (Fudenberg and Tirole, 1998). The result is that frequent upgrading in the form of a rapid succession of new product generations can provide some consumers with an incentive to delay their purchase and possibly seek an alternative.

From the above analysis, it seems that frequent upgrading can potentially increase demand. On the other hand, frequent upgrading might also lead to a phenomenon known as the "disappearance market". Overall, our a priori expectation is that the increase in demand due to upgrading is greater than the demand disappearance. This leads to the first hypothesis in this study:

Hypothesis 1: Quality upgrading is an effective method to increase sales of computers. 
While a consumer may have an incentive to delay a purchase, the decision to wait comes with a cost. The consumer must delay realizing the benefit associated with ownership of the product. However, due to the short product life cycles typical of computers, the consumer can reasonably expect the cost of waiting to be low as the amount of time she must wait is short. This is especially true for a consumer who already owns one product which may still have sufficient practical utility to her. It might be the historical practice of frequent upgrading and rapid, aggressive price cuts that send the signal that the cost of waiting will be low.

In fact, steep price cuts will only entice the consumer to purchase if the immediate gain in adjusted consumer surplus is greater than the anticipated consumer surplus associated with the new generation of product (less the cost of waiting). In the case of IT products, quality has been increasing at an exponential rate (Barro et al. 1999). This suggests the possibility that the future benefit associated with a dramatically lower quality-adjusted price will far outweigh the immediate benefit of a price cut for the current generation (Varian, 1997; Krantz et al., 1971; Hagerty, 1978). This leads to our second hypothesis in this study:

Hypothesis 2: Lowering price will increase sales of computers.

Underlying Hypothesis 1 and Hypothesis 2 is the supposition that the demand for computers is perhaps highly elastic relative to price. This suggests that computers are seen as luxury goods by consumers. If computers are seen as luxury goods, then the expectation is that sales of computers will increase as expenditure increases (Silberberg, 2000; Klonaris and Hallam, 2003). This leads to our third hypothesis in this study:

Hypothesis 3: Increasing sales of computers are attributed to an increase in expenditure.

In order to test Hypotheses $\mathbf{1}-\mathbf{3}$ we conduct our analysis using aggregate industry level data. The motivation for the use of aggregate data is that, due to differences between individual products, a product level analysis may not yield accurate results unless a very large number of products are included in the analysis. The range of products would have to span different types of computers, from different vendors, and target different customer groups (e.g. home users and business users) in order to yield meaningful results. A sufficiently broad data set was simply not available.

The use of aggregate data to explore these kinds of trends has precedent in the literature. (Dutta, 2001) investigates a causal relationship between telecommunications infrastructure and overall economic activity by using country-level data. For the impact of IT investments on productivity, a number of industry-level analyses have been performed on aggregate data sets (Baily, 1986; Hackett, 1990; Panko, 1991; Roach, 1987; Strassman, 1990).

\section{Data And Non-Stationary Tests}

\subsection{Data}

The data used in this study include the season-adjusted end-of-month sales of computers, the monthly producer price index for electronic computers, monthly personal expenditure on durable and non-durable goods, the monthly consumer price index, and the monthly inventory/sales ratio for electronics and appliance stores and for total retail trade from January 1992 to February 2002. Please see Table 1 for the descriptions and sources of all data used in the paper. It is worthwhile to mention that the use of aggregate data to explore industry and sector-level concerns has precedent in the business and economics literature. Previous research utilizing aggregate data from 30 countries suggests a causal relationship between telecommunications infrastructure and overall economic activity (Dutta 2001). And in the general vein of estimating the impact of IT investments on productivity, a number of industry-level analyses have been performed on aggregate data sets (Baily 1986, Hackett 1990, Panko 1991, Roach 1987 and 1991, and Strassman 1990).

In general, computer buyers can be categorized as either individual consumers or business consumers. In our analysis, we use monthly personal expenditure on both durable and non-durable goods as computers are composed of durable and non-durable goods. Unfortunately, we only have the quarterly data for private investment 
instead of monthly data. Fortunately, we find that quarterly private investment is highly correlated with quarterly personal expenditure with a coefficient of 0.90 during our analysis periods (From the first quarter in 1992 to the first quarter in 2002). This indicates that personal expenditure moves in almost the same manner as private investment. So, we are confident in using monthly personal expenditure to aggregate monthly personal expenditure and private investment. The ability to aggregate monthly personal expenditure and private investment is advantageous as it affords the ability to use more observations, which is important to time series data analysis.

Table 1: Data Descriptions and Sources

\begin{tabular}{|c|c|c|c|}
\hline & Data & Description & Source \\
\hline 1 & $\begin{array}{l}\text { Adjusted estimates of monthly retail } \\
\text { for computer and software stores in } \\
\text { million\$ (January 1992-February } \\
\text { 2002) }\end{array}$ & $\begin{array}{l}\text { Retail sales of new computers, computer } \\
\text { peripherals, and prepackaged computer software } \\
\text { in combination with repair and support services }\end{array}$ & $\begin{array}{l}\text { US Census Bureau, US } \\
\text { Department of Commerce }\end{array}$ \\
\hline 2 & $\begin{array}{l}\text { Monthly producer price index for } \\
\text { electronic computers (January 1992- } \\
\text { February 2002) }\end{array}$ & $\begin{array}{l}\text { A family of indexes that measures the average } \\
\text { changes over time in selling prices received by } \\
\text { domestic producers of goods and services from } \\
\text { the perspective of the seller. }\end{array}$ & $\begin{array}{l}\text { Bureau of Labor Statistics, } \\
\text { US Department of Labor }\end{array}$ \\
\hline 3 & $\begin{array}{l}\text { Monthly personal expenditure on } \\
\text { durable and non-durable goods in } \\
\text { billion } \$ \text { (January 1992-February } \\
\text { 2002) }\end{array}$ & $\begin{array}{l}\text { Household expenditure on durable and non- } \\
\text { durable goods }\end{array}$ & $\begin{array}{l}\text { Bureau of Economic } \\
\text { Analysis, US Department of } \\
\text { Commerce }\end{array}$ \\
\hline 4 & $\begin{array}{l}\text { Monthly consumer price index } \\
\text { (January 1992-February 2002) }\end{array}$ & $\begin{array}{l}\text { Changes in the prices paid by urban consumers } \\
\text { for a representative basket of goods and services. }\end{array}$ & $\begin{array}{l}\text { Bureau of Labor Statistics, } \\
\text { US Department of Labor }\end{array}$ \\
\hline 5 & $\begin{array}{l}\text { Monthly inventory/sales ratio for } \\
\text { electronics and appliance store and } \\
\text { for total retail trade (January 1992- } \\
\text { February 2002) }\end{array}$ & $\begin{array}{l}\text { The ratio of inventories/sales for electronics and } \\
\text { appliance store and for total retail trade }\end{array}$ & $\begin{array}{l}\text { US Census Bureau, US } \\
\text { Department of Commerce }\end{array}$ \\
\hline
\end{tabular}

To eliminate distortions due to inflation, data (initially in nominal value) are adjusted to real values by taking January 1992 as a base month. The quality and price indexes are based on the January 1992 level of 100. Since the producer price index does not consider the quality changes of products, i.e. it is not a hedonic price index, we compile the ratio of the Quality/Price series. This approach is consistent with previous research on the pricequality tradeoff (Hagerty 1978, Krantz et al. 1971, and Varian 1992 and 1997). Following traditional research methods, most of the data series are transformed into logarithmic values for analysis.

A major concern in this work is the difficulty of capturing a meaningful estimate of the quality difference among products through time. To our knowledge, there is presently no such quality index available at hand. The closest we have seen are the quality-adjusted prices discussed previously. However, in those cases quality-adjusted prices are calculated based on punctuated observations and the assumption that the rate of change in the qualityadjusted price can be approximated by a function that fits these data points. This is problematic as it is essential that we incorporate the quality factor in our analysis. Therefore, we have derived an index to approximate the evolution of computer quality. The index is discussed in detail in Appendix A.

\subsection{Non-Stationary Tests}

As time series variables with unit roots may lead to spurious estimation, we first test whether they are stationary. Following McKenzie and Brooks (1999), we conduct one informal and two formal tests for unit roots. The informal and intuitive test is to inspect the Auto-Correlation Function (ACF) and Partial Auto-Correlation Function (PACF) diagrams. Figure 1 presents the ACF and PACF for the monthly logarithmic series of computer sales (we find similar ACF and PACF patterns for the monthly logarithmic series of the quality/price ratio and personal expenditure). Figure 1 suggests that non-stationarity exists in the data, as two readily distinguishable 
features can be easily found. First, the ACF exhibits a very slow rate of decay as the lag length increases and second, the PACF contains a large and statistically significant spike at the one period lag, and it almost disappears after that.

Figure 1: ACF and PACF for the Sales in Level

\begin{tabular}{|c|c|c|c|c|c|c|c|c|}
\hline \multicolumn{2}{|c|}{ Autocorrelation } & \multicolumn{2}{|c|}{ Partial Correlation } & \multicolumn{2}{|r|}{$\mathrm{AC}$} & PAC & Q-Stat & Prob \\
\hline I & & 1 & & 1 & 0.969 & 0.969 & 117.47 & 0.000 \\
\hline I & & 1 & 1 & 2 & 0.936 & -0.064 & 227.85 & 0.000 \\
\hline I & & 1 & 1 & 3 & 0.906 & 0.049 & 332.18 & 0.000 \\
\hline I & & 1 & I. 1 & 4 & 0.880 & 0.038 & 431.41 & 0.000 \\
\hline I & & 1 & 1 & 5 & 0.853 & -0.021 & 525.54 & 0.000 \\
\hline I & & 1 & 1 & 6 & 0.827 & 0.001 & 614.78 & 0.000 \\
\hline I & & 1 & 1 & 7 & 0.801 & -0.023 & 699.09 & 0.000 \\
\hline i & & 1 & i & 8 & 0.772 & -0.039 & 778.26 & 0.000 \\
\hline I & & 1 & 1 & 9 & 0.743 & -0.027 & 852.25 & 0.000 \\
\hline I & & 1 & 1 & 10 & 0.712 & -0.057 & 920.76 & 0.000 \\
\hline I & & 1 & 1 & 11 & 0.680 & -0.033 & 983.80 & 0.000 \\
\hline I & & 1 & 1 & 12 & 0.652 & 0.043 & 1042.3 & 0.000 \\
\hline I & & 1 & 1 & 13 & 0.622 & -0.060 & 1095.9 & 0.000 \\
\hline I & & $1]$ & 1 & 14 & 0.597 & 0.071 & 1145.8 & 0.000 \\
\hline I & & 1 & 1 & 15 & 0.570 & -0.048 & 1191.7 & 0.000 \\
\hline I & & 1 & 1 & 16 & 0.541 & -0.039 & 1233.6 & 0.000 \\
\hline 1 & & 1 & 1 & 17 & 0.510 & -0.050 & 1271.0 & 0.000 \\
\hline I & & $1]$ & ] & 18 & 0.480 & 0.002 & 1304.6 & 0.000 \\
\hline 1 & & 1 & 1 & 19 & 0.451 & -0.031 & 1334.4 & 0.000 \\
\hline 1 & & $1]$ & 11 & 20 & 0.422 & -0.004 & 1360.8 & 0.000 \\
\hline
\end{tabular}

Figure 2: ACF and PACF of the Sales in $1^{\text {st }}$ Difference

\begin{tabular}{|c|c|c|c|c|c|c|}
\hline Autocorrelation & Partial Correlation & & $\mathrm{AC}$ & PAC & Q-Stat & Prob \\
\hline I & 111 & & -0.059 & -0.059 & 0.4247 & 0.515 \\
\hline & & & -0.224 & -0.228 & 6.6927 & 0.035 \\
\hline 11 & 11 & 3 & 0.024 & -0.006 & 6.7624 & 0.080 \\
\hline 1 1 & 1 & 4 & 0.124 & 0.078 & 8.7131 & 0.069 \\
\hline 11 & 11 & & -0.029 & -0.011 & 8.8203 & 0.116 \\
\hline a & ， & 6 & 0.139 & 0.192 & 11.328 & 0.079 \\
\hline$[1$ & 1 & & -0.006 & 0.008 & 11.332 & 0.125 \\
\hline 1 & 1 & 8 & 0.016 & 0.083 & 11.364 & 0.182 \\
\hline$f_{1}$ & $1 F_{1}$ & 9 & 0.087 & 0.103 & 12.360 & 0.194 \\
\hline $\mathbf{f}_{1}$ & $F_{1}$ & 10 & 0.101 & 0.108 & 13.733 & 0.186 \\
\hline$[1$ & $1 / 1$ & 11 & -0.024 & 0.044 & 13.809 & 0.244 \\
\hline 1 & 1 & 12 & -0.008 & 0.000 & 13.818 & 0.312 \\
\hline 111 & 11 & 13 & -0.041 & -0.069 & 14.051 & 0.370 \\
\hline 11 & $1] 1$ & 14 & 0.061 & 0.012 & 14.563 & 0.409 \\
\hline 11 & 11 & 15 & 0.079 & 0.031 & 15.445 & 0.420 \\
\hline $1 \boldsymbol{F}_{1}$ & 1 & 16 & 0.113 & 0.118 & 17.269 & 0.368 \\
\hline $1[1$ & 1 & 17 & -0.008 & 0.044 & 17.277 & 0.436 \\
\hline 1 & 1 1 & 18 & 0.005 & 0.039 & 17.280 & 0.504 \\
\hline 11 & 11 & 19 & 0.066 & 0.076 & 17.913 & 0.528 \\
\hline 1 & $1[1$ & 20 & -0.060 & -0.098 & 18.438 & 0.559 \\
\hline
\end{tabular}

The popularly used formal tests for non-stationarity in the literature are the Augmented Dicky-Fuller (ADF) and Phillips-Perron (PP) tests. In this paper, the ADF test is conducted assuming 5 period lags with and without time trend. For the PP test, the lag period is 4 with and without time trend. Table 2 presents the results of the $\mathrm{ADF}$ and PP tests for each of the three time series. From Table 2, we can see that (except for one case) each of the two versions of the ADF test clearly fail to reject the null hypothesis of a unit root in each series at $\alpha=.05$ as the test value is less than the MacKinnon critical value in all but one instance. Each of the two PP tests generates (absolute) values that are less than the critical test value at $\alpha=.05$. This again is suggestive of the presence of nonstationarity in computer sales, personal expenditure, and quality/price series.

Table 2: Augmented Dickey-Fuller (ADF) and Philips-Perron (PP) Stationary Testing of Monthly Logarithmic Values

\begin{tabular}{|c|c|c|c|}
\hline & $\ln ($ Sales $)$ & $\ln$ (Quality/Price) & $\ln ($ Expenditure $)$ \\
\hline ADF with intercept, lag=5 $(-2.8863)$ & $-3.0493 *$ & -0.2293 & 0.3003 \\
\hline ADF with intercept and time trend, lag=5 $(-3.4487)$ & -0.9160 & -1.6402 & -1.4487 \\
\hline PP with intercept, lag=4 (-2.8853) & -2.8327 & -0.0935 & 0.6230 \\
\hline PP with intercept and time trend, lag=4 $(-3.4472)$ & -0.8109 & -2.0906 & -2.4990 \\
\hline
\end{tabular}

Notice: Critical-statistics in parentheses for $\mathrm{ADF}$ and PP stationarity testing at $\alpha=.05$. * Means significant at $\alpha=.05$. A (absolute) value greater than the critical t-value indicates non-stationarity.

The conventional way to eliminate a unit root is to take differences until stationarity is established. The first difference in a logarithmic series is calculated as $\Delta \ln V_{t}=\ln V_{t}-\ln V_{t-1}=\frac{V_{t}-V_{t-1}}{V_{t-1}}$ (when $\Delta V_{t}$ is small, where $V$ is a time series), which approximates the continuously compounded growth rate. The correlogram of the first difference for logarithmic values of computer sales is presented in Figure 2.

From Figure 2, we can see that, in contrast to time series in level, the decay in the ACF and large spike in the PACF have been eliminated. (Similar ACF and PACF patterns of the first difference for the logarithmic values of the quality/price ratio and personal expenditure were also found.) Table 3 presents the details of ADF and PP tests for the three time series in the first difference. 
Table 3: Augmented Dickey-Fuller (ADF) and Philips-Perron (PP) Stationarity Testing of Growth Rates

\begin{tabular}{lccc}
\hline \hline & Sales $_{\mathrm{g}}$ & (Quality/Price) $_{\mathrm{g}}$ & Expenditure $_{\mathrm{g}}$ \\
\hline ADF with intercept, lag=5 (-2.8865) [-3.488] & $-3.4147^{*}$ & $-5.4576^{* *}$ & $-4.7771^{* *}$ \\
ADF with intercept and time trend, lag=5 (-3.4491) [-4.0400] & $-4.2144^{* *}$ & $-5.4301^{* *}$ & $-5.7707^{* *}$ \\
\hline PP with intercept, lag=4 (-2.8855) [-3.4856] & $-11.7632^{* *}$ & $-12.1678^{* *}$ & $-18.3140^{* *}$ \\
PP with intercept and time trend, lag=4 (-3.4475) [-4.0367] & $-12.9267^{* *}$ & $-12.1143^{* *}$ & $-18.3130^{* *}$ \\
\hline \hline
\end{tabular}

Note: Critical-statistics in parentheses and brackets for ADF and PP stationarity testing at $\alpha=.05$ and $\alpha=.01$ levels respectively. * Means significant at $\alpha=.05$. ** Means significant at $\alpha=.01$. A (absolute) value greater than the critical t-value indicates nonstationarity.

We find evidence to suggest the stationarity of the three time series in the first difference. All other test values (in absolute) are greater than the critical value at $\alpha=.01$ except for the ADF test with intercept for sales, which is significant at $\alpha=.05$. This result is not sensitive to the presence of an intercept term (which would signify a time trend). Hence, the ADF and PP tests in this instance clearly indicate that the growth rates for computer sales, expenditure, and the ratio of quality/price are stationary. Therefore, we conclude that the three monthly time series in level are integrated in order one, I(1), and may be cointegrated with each other. We conduct cointegration analysis in next section.

\section{Cointegration, Vector Error Correction (Vec) Model And Empirical Results}

Cointegration analysis, first introduced in the seminal work of Engel and Granger, (both Noble laureates in Economics in 2003 for their research on cointegration analysis and the ARCH model), is used to investigate longterm trends (Engle and Granger 1987; Johansen and Juselius 1990). A set of time series variables are cointegrated if they are integrated at the same level and a linear combination of these variables is stationary. The linear combination would measure a long-term relationship among these variables (see Hold and Perman 1994 for an excellent discussion of cointegration). In cointegration analysis it has been shown that by setting up an error-correction model (ECM) the short-term movement (dynamic process) among variables and their adjustment process towards longterm equilibrium (static state) can be established (Mayasami and Koh 2000). In general, ECM is thought to provide better short-term forecasts and more economically meaningfully long-term forecasts than other methods (Granger 1996). Therefore, cointegration analysis and ECM not only offer insights into the properties of computer sales, but also provide a valid tool to forecast the market movements. For more information on the use and effectiveness of ECM, see LeSage(1990), Engle and Granger(1987), Hoffman and Rasche(1996), and Lin and Tsay(1996).

\subsection{Error Correction Model}

An error correction model (ECM) is applicable in our analytical framework because it not only builds in cointegration, but also measures the short-term adjustment. The vector error correction model (VECM) is more efficient than Engle-Granger's two-step ECM because VECM is a full information maximum likelihood estimation model and it tests cointegration in the full system of equations in a single step, without requiring a specific variable to be normalized (Engle and Granger 1987, Mayasami and Koh 2000). VECM is also appropriate because we suspect, a priori, that there will be two cointegrating relationships among computer sales, quality/price ratio, and expenditure, so a two-step ECM approach is not suitable in this context.

The first step in constructing the VEC model is to conduct the ADF and PP tests for stationarity of the variables in levels and in the first difference. Only variables integrated of the same order may be cointegrated. In section 4 , we have performed these tests and have reached the conclusion that the three time series of computer sales, expenditure, and the ratio of quality/price in level are I(1). Next, we test whether and/or how many cointegration equations exist among them. 
Table 4: Johansen-test for Cointegration

\begin{tabular}{llllllll}
\hline \hline $\begin{array}{l}\text { Hypothesized } \\
\text { No. of CE(s) }\end{array}$ & Eigenvalue & $\lambda_{\text {trace }}$ & $\begin{array}{l}\text { CV } \\
\text { (trace 5\%) }\end{array}$ & $\begin{array}{l}\text { CV } \\
\text { (trace 1\%) }\end{array}$ & $\lambda_{\max }$ & $\begin{array}{l}\text { CV } \\
(\max 5 \%)\end{array}$ & $\begin{array}{l}\text { CV } \\
(\operatorname{max~1\% )~}\end{array}$ \\
\hline None $*$ & 0.1759 & $33.4440^{*}$ & 29.68 & 35.65 & $22.2476^{*}$ & 20.97 & 25.52 \\
At most 1 & 0.08112 & 11.2964 & 15.41 & 20.04 & 9.7288 & 14.07 & 18.63 \\
At most 2 & 0.0135 & 1.5676 & 3.76 & 6.65 & 1.5676 & 3.76 & 6.65 \\
\hline \hline
\end{tabular}

Note: $*(* *)$ denotes rejection of the hypothesis at $\alpha=.05(\alpha=.01)$ significance level.

L.R. test indicates 1 cointegrating equation(s) at $\alpha=.05$.

$\mathrm{CE}$ : Cointegration Equation, CV: Critical Value.

We use EViews Version 4.0 (2000) to conduct the Johansen-test for cointegration and run VECM regressions. Table 4 presents the Johansen-test for the cointegration of the sales of computers, the quality/price ratio, and personal expenditure. As both $\lambda_{\text {trace }}$ and $\lambda_{\max }$ are greater than the critical values at $\alpha=.05$, the test results suggest that there is one cointegration.

Table 5: Vector Error Correction with One Cointegrating Equation

\begin{tabular}{|c|c|c|c|c|}
\hline $\begin{array}{c}\text { Normalized } \\
\text { Cointegration Equation }\end{array}$ & $\ln$ (Sales) & Constant & $\ln$ (Quality/Price) & $\ln ($ Expenditure) \\
\hline Coefficient & 1 & 222.5882 & $\begin{array}{c}1.5635 \\
(2.8424) \\
\end{array}$ & $\begin{array}{l}-27.7834 \\
(-2.6251) \\
\end{array}$ \\
\hline Parameter & $\ln$ (Sales) & & ln(Quality/Price) & ln(Expenditure) \\
\hline$\alpha$ & $\begin{array}{l}-0.0175 \\
(-2.6718) \\
\end{array}$ & & $\begin{array}{c}0.0074 \\
(0.3771) \\
\end{array}$ & $\begin{array}{c}0.0021 \\
(2.7793) \\
\end{array}$ \\
\hline Constant & -0.0200 & & 0.0568 & 0.0062 \\
\hline
\end{tabular}

Note: t-value in parenthesis.

Table 5 shows the main regression results of the VEC models with one cointegrating relationship. Normalizing the cointegration with respect to computer sales, the cointegrating equation ( $\mathrm{t}$-values in parentheses) shows the following relation:

$\ln ($ Sales $)=-222.5882-1.5635 \ln ($ Quality/Price $)+27.7834 \ln ($ Expenditure $)$

This cointegration equation is a long-term relationship amongst the computer sales, the quality/price ratio, and consumer expenditure. The estimated coefficients of the quality/price ratio and personal expenditure are significant at $\alpha=.01$. The sign of the estimated coefficient for expenditure is positive as expected, which supports Hypothesis 3. This implies as expenditure increases, the sales of computers will increase. Moreover, the coefficient of expenditure measures the income elasticity of demand for computers. The coefficient value of 27.7834 is clearly greater than 1. According to economic theory, this implies that computers are generally considered luxury goods, as when expenditure increases, the share of expenditure allocated to computers increases even faster (see Varian 1992). However, the sign of the estimated coefficient for quality/price is negative, which rejects Hypotheses $\mathbf{1}$ and $\mathbf{2}$. This result is contradictory to our initial expectation, as we believed that given the price level, increasing quality should result in a corresponding increase in sales. The negative sign suggests that when the quality of computers becomes more affordable, i.e. the ratio of quality/price becomes higher, the total sales will decrease (assuming all other factors remain constant). 
In the cointegration equation, if $\ln ($ Quality/Price) is converted to $(\ln$ (Quality)- $\ln ($ Price $)$ ), the negative sign of the $\ln$ (Quality/Price) means that the sign of the implicitly estimated coefficient for $\ln$ (Price) is positive ${ }^{1}$. Therefore, a positive relationship exists between price and sales, that is, higher prices bring higher revenues and lower prices result in lower revenues. The rationale is that although higher prices can result in a reduction in interested buyers, the additional accrued revenue due to the higher price is higher than the lost revenue due to the loss of consumers.

However, when lowering prices, the accrued revenue from the attraction of additional buyers cannot cover the lost revenue that results from lowering prices. This suggests that the elasticity of demand for computers with respect to price is less than 1 , i.e. the demand for computers is inelastic ${ }^{2}$.

Recall the ADF and PP tests in Section 4. The tests show that the growth rates (the first difference of logarithmic values) of computer sales, Quality/Price, and expenditure are stationary. So we can regress the growth rate of sales $\left(\right.$ Sales $_{g}=\Delta \ln ($ Sales $\left.)\right)$ on the Quality/Price ratio and expenditure growths by using ordinary least square (OLS). The regression results are as follows:

$$
\begin{array}{ccc}
\text { Sales }_{g}=0.00406+0.0107\left(\text { Quality }_{\text {Price }}\right)_{g} & +1.4490 \text { Expenditure }_{g} \\
(0.3296) & (2.1027) & \\
R^{2}=0.04 \quad \text { Log likelihood }=252 & \text { DW Statistic }=2.06 \quad \text { F Statistic }=2.24
\end{array}
$$

The estimated coefficient for the Quality/Price ratio is positive, but insignificant. The estimated coefficient for expenditure is 1.449 , which is significant at $\alpha=.05^{3}$. The DW statistic is close to 2 , which suggests that there is no autocorrelation and the $\mathrm{F}$ statistic is significant at $\alpha=.01$. The result of the regression supports the result derived from the cointegration equation above, which suggests that growth in expenditure drives growth in computer sales.

We now explore the short-term adjustment of computer sales. In Table 5, the adjusting speed for computer sales is 0.0175 , which is significant at $\alpha=.01$. This suggests that computer sales adopt a convergence of short-run deviations toward long-run equilibrium with a speed of 0.0175 . The low adjusting speed means that it takes a long time for computer sales to adapt to changes in the quality/price ratio and personal expenditure, if any deviation of quality, price or expenditure from long-term equilibrium occurs.

If we combine the long-term relationships with the short-term error corrections and only consider the lag variables significant at $\alpha=.05$, the regression result for computer sales with the other variables in the VECM is as follows:

$$
\begin{aligned}
& \Delta \ln (\text { Sales })_{t}=-0.0200-0.2730 \Delta \ln (\text { Sales })_{t-2}-2.6069 \Delta \ln (\text { Quality } / \operatorname{Pr} \text { ice })_{t-4} \\
& -0.0175[222.5882+\ln (\text { Sales })+1.5635 \ln (\text { Quality } / \text { Price })-27.7834 \ln (\text { Expenditure })] \\
& R^{2}=0.21 \quad \text { Log likelihood }=251 \quad \text { F-Statistic }=1.35(\text { F-Statistic is significant at } \alpha=.1)
\end{aligned}
$$

\footnotetext{
${ }^{1}$ Suppose $d s / d(q / p)=-b$, where $s$ is sales, $q$ is quality, $p$ is price and $b$ is a constant and greater than 0 . This means $d s=-b * d(q / p)$. Given $q$ is fixed, $d s=\left(b * q / p^{2}\right) d p$. Therefore, $d s / d p=b *\left(q / p^{2}\right)>0$, which is positive.

${ }^{2} \mathrm{~s}=\mathrm{p}^{*} \mathrm{x}$, where $\mathrm{s}$ is sales, $\mathrm{p}$ is price and $\mathrm{x}=\mathrm{x}(\mathrm{p})$ is quantity. $d s / d p=x+p^{*} d x / d p$. Suppose $(d x / d p)^{*}(\mathrm{p} / \mathrm{x})=\mathrm{a}$, where a is the price elasticity and less than $0 . d s / d p=x(p)+p *(x / p) * a=x+x * a=x(1+a)$. Given $d s / d p>0$, we get $0>a>-1$. So the price elasticity of $x$ is inelastic.

${ }^{3}$ The $\mathrm{R}^{2}$ is quite low but, in general, econometricians are more concerned with obtaining "good" parameter estimates where "good" is not necessarily defined in terms of $\mathrm{R}^{2}$. Therefore, when compared with other measurements such as unbiasedness, efficiency, and MSE, $\mathrm{R}^{2}$ is not of paramount importance in econometrics (Kennedy, 1998).

${ }^{4} R^{2}$ can be ignored due to nonlinear estimation (Kennedy, 1998).
} 


\section{Discussion And Implications}

We have found that long-term relationships among computer sales, the quality/price ratio, and consumer expenditure are present. Specifically, we show that increases in computer sales are mainly due to increasing expenditure. In addition we also find a low adjusting speed for the convergence of short-run deviations to a long-run sales equilibrium and that increases in quality are not highly valued in terms of the revenue increase. These finding have implications with respect to the impact of product upgrading and price reduction as strategies to boost sales.

\subsection{Frequent Upgrading}

Frequent upgrading, while expanding product functionality and serving to reinvigorate the market, is not entirely a good thing. A number of issues need to be considered, including cannibalization of existing product sales and customer reaction to "planned obsolescence". Regarding the latter, research suggests that consumers are beginning to revolt against the steady stream of upgrades (Bulkeley 1990). The complaint being that upgrading hardware is expensive in terms of money and in terms of the time needed to learn how to install and use the upgrade. Compatibility with existing infrastructure is also a concern and upgrading mission critical software can entail the need to upgrade hardware and vice-versa. The result of this backlash against upgrading can manifest as lackluster demand for new versions when an older version has not outlived its practical utility. The failure of newer versions to "catch on" is sometimes referred to as the "disappearing market" phenomenon.

\subsection{Price Promotions}

Lowering prices, whether due to planned price promotions or in response to the all too common price war, can potentially suppress overall sales growth. This is because the accrued revenue from the attraction of additional buyers cannot cover the lost revenue that results from lowering prices. This suggests that the elasticity of demand for computers with respect to price is less than 1, i.e. the demand for computers is inelastic. So while the size of the market may grow in terms of quantity, the dollar value will shrink. Given that it will take a long time for sales to respond to any deviation in quality, price or expenditure, planned price promotions should be seen as strategies that not only impact short-term sales, but also long-term sales. So while a price promotion effort may trigger an initial increase in sales, the long-term market impact should also be considered.

\subsection{Generic Marketing}

If product upgrading and price promotions were strictly voluntary efforts on the part of individual companies, then a straightforward recommendation would be to reduce the rate of new product introduction and back off on the price reductions. In reality, aggressive price-cutting is made necessary by drastically falling production prices and fierce competition. If a given company attempts to maintain prices, a competitor will undercut them and take their market share. The same is true for new product versions. Customers demand functionality, performance, speed, reliability, and compatibility. New versions of computers offer improvements in those areas, usually at a much lower quality-adjusted price. To delay bringing innovation to the market place is to invite a competitor to capture market share. In this sector, market competitive forces may necessitate that price-cutting and new product introduction occur at a rate that is detrimental to overall sales growth.

Given that the driver of sales growth for computers is household expenditures and business firm investments and the unanimous consensus that a great deal of sales potential remains untapped, generic marketing seems to be an attractive strategy. In this setting generic advertising can be used as an alternative strategy to price promotion and product upgrading (to the extent that these tactics are voluntary), or as a supplement to offset the negative effect of price promotion and product upgrading when market competitive forces dictate that these occur at a rate that is harmful to overall sales growth. The underlying logic is that by increasing primary demand generic advertising can help invigorate the market while allowing each market player to be maximally competitive. 
Generic advertising can be executed in two different ways. First, individual firms can run generic campaigns. The campaign is developed and funded by an individual company, but the thrust of the advertising is not brand specific. For companies in this sector such a strategy could prove very effective as there are decreasing demand returns to product variety for brand multi-product firms (i.e. for a given firm different products are seen as close substitutes) (Hui, 2004). Multiple companies may also simultaneously run different independent generic advertising campaigns. For example, for satellite radio, both Sirius and XM run independent generic campaigns that highlight the benefits of satellite ratio over conventional radio that do not mention themselves or their competitors (Beardi 2001, Boston and Halliday 2003).

On the other hand, it is possible to conduct a generic advertising campaign that invokes certain attributes that will cause consumers to value the advertisers' products more than their competitors. In this manner a firm can simultaneously "grow the pie" and try to get a bigger slice. For example, a generic orange juice campaign that emphasized nutrition and taste would benefit companies that had differentiated themselves based on taste, such as Tropicana.

While the possibility of growing the pie and growing the slice makes generic advertising conducted by individual firms seem attractive, it also entails duplication of effort and possible inefficiencies. Lack of coordinated campaigns can result in poor advertising coverage in some areas and inundations in other areas. The same money spent in a coordinated fashion could have been more effective at growing the market. The benefits of coordination and efficiency justify the second, most common, form of executing generic advertising campaigns: advertising consortiums.

Presently there are a number of examples of consortiums in the IT industry, from standards setting consortiums such as the WWWC, to "quality" consortiums such as the Maryland Software Industry Consortium (http://www.mdswic.org/), to a number of R\&D consortiums. However, there is currently nothing in the technology arena that rises to the level of advertising coordination and impact seen in industries such as agriculture and plastics. In this setting a consortium could be appealing to a number of firms because the sales of computers are so closely inter-twined. For example, the makers of PC peripherals will benefit with stronger PC shipments, which also entails increased sales of packaged software. As a result, all would be interested in expanding the size of the market.

\section{Conclusions And Limitations}

This paper offers several contributions that are beneficial to marketing and sales professionals as well as academic researchers. The key findings of this work are of significant practical importance to managers in firms associated with computers. Specifically, we find that common industry practices such as aggressive price-cutting and frequent upgrading are potentially counter-productive strategies. These strategies can have the net effect of suppressing long-terms sales and impeding industry growth. We also provide recommendations, namely generic advertising and advertising consortiums, which will enable businesses to act on the trends identified in this paper. In addition, we have taken some first steps toward the compilation of a computer quality index and the incorporation of the quality factor into an empirical analysis of the sales of computers.

While our findings are interesting, the work presented here is not without its limitations. First, while in practice sales revenues are obtained from both sales and services, this paper only focuses on sales. It is possible that increased revenue from services could offset lost sales, or even replace them entirely, and that possibility should be explored. Second, due to limited data access, we use personal expenditure as a proxy measure of the total expenditure of households and firms. Although quarterly personal expenditure is highly positively correlated with quarterly firm investment, our research would be more rigorous if the data for monthly private investment was available. Third, our results are dependent on the validity of the quality index we have employed. A great deal of work remains to be done in the general area of comparing the quality of items that evolve over time, ours is a first step, but rarely is the journey limited to a single step. Fourth, since our results are based on aggregate data, two concerns immediately come to mind. The first is that we lump business and consumer spending, these markets may behave in very different manners and should be analyzed separately. The second is that the conclusions reached in 
this paper may not be valid across all types of computers; therefore organizations should test the conclusions of this paper on their own data for validity.

Additional areas for future research include exploring an optimal upgrading strategy and using the VEC model as a decision support tool for forecasting computer sales. In addition, more detailed studies using company specific sales data could provide additional insights into the trends observed here.

\section{Appendix A: The Quality Index For Computers}

In the literature many definitions for "quality" exist, such as "Quality is excellence." and "Quality is value." (Reeve and Bednar 1994). In this paper, we use a broad definition of quality: "the ability of a product or service to consistently meet or exceed customer expectation." (Stevenson 2002). By this definition, the dimensions of quality in the context of computers refer to the performance and special features of the product. Since it is impossible to include all factors that impact perceived quality we focus on a set of factors that are (a) persistent over the data time horizon and (b) fairly representative of factors that are considered desirable by mainstream users. Table A1 shows the factors chosen for inclusion in the quality index. Although we omit some factors commonly seen in PC's, we believe that they will move in the same direction, and at a similar speed, as the factors shown in Table A1.

The data was collected from PC World, PC Magazine and PC Computing from January 1992 to February 2002. For non-quantitative data, we assign a reasonable base value to them according to their magnitudes of importance to consumers. The weights assigned to each factor are chosen in accordance with surveys regarding the factor's importance in terms of quality consideration in PC World. Also, we use adaptive weights to reflect that some of the factors become more or less important to quality as time goes on. For example, hard disk capacity was a significant quality consideration 10 years ago, but due to decreased costs of storage capacity, it is not a major driver of quality evaluation today. So, we decrease the weight assigned to hard disk capacity for the more recent data. We then compile the quality index as a linear function of the factors in Table A1, and use the corresponding weight as the coefficient for each factor.

Table A1: Dimensions of the Quality Index

\begin{tabular}{cccc}
\hline \hline Factor & Measurement & Base Value & Weight \\
\hline CPU & Speed (Mhz) & 33 & 0.5 \\
RAM & Capacity (Mb) & 4 & 1 \\
Hard Disk & Capacity (Mb) & 340 & $0.4-0.18$ \\
Cache & Capacity (Kb) & 128 & 0.01 \\
Multimedia & CD Rom, MPEG Decoder, Sound Card etc. & 10 & $0.2-1$ \\
Monitor & Size & 10 & 0.1 \\
CD Rom, CD RW, DVD Rom & Speed & 50 & 0.08 \\
Others & Mouse, USB, Zip Drive, OS etc. & 10 & 1.05 \\
\hline \hline
\end{tabular}

The compiled quality index is illustrated in Figure A1. The ladder shape of the quality index is consistent with the findings previous quality research (Barro and Martin 1999), (Wang, Gopal and Tung 1997). The rapidly rising quality index indicates that the quality of IT products increases exponentially. This is consistent with the theoretical research on the behavior of the aggregate quality index given by Barro and Martin (1999) who employ the following definition of the aggregate quality index: $Q_{t}=\sum_{j=1}^{t} q^{k_{j} \alpha(1-\alpha)}$, where $Q_{t}$ is the aggregate quality index at time $t, q$ is the quality level, $k_{j}$ is the improvement in quality in time $j$, and $0<\alpha<1$. Taking logarithmic values of the index we can see the new, nearly straight, line in Figure A2 which illustrates this exponential increase in quality. Although this is the first time such a quality index has been compiled in this setting, we are optimistic that the index can approximate the quality improvements of computers over time and is a reliable instrument for this research. 

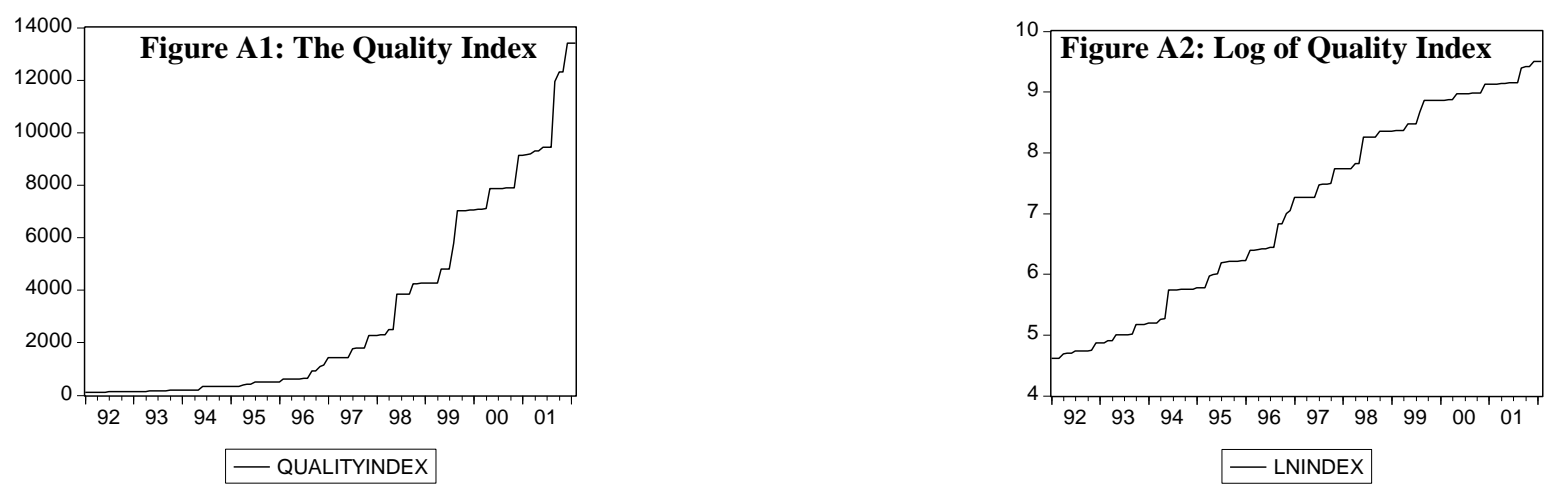

\section{References}

1. Baily, M. (1986) What has happened to productivity growth? Science, vol. 234, pp. 443-451.

2. $\quad$ Barro, R.J., and X. Sala-I-Martin (1999) Economic Growth. The MIT Press.

3. Bass, F.M., A. Krishnamoorthy, A. Prasad, and S.P. Sethi (2004) Generic and Brand Advertising Strategies in a Dynamic Duopoly. Working paper. University of Texas at Dallas.

4. $\quad$ Berndt, E., and Griliches, Z. (1993) Price indices for microcomputers: an exploratory study in Foss, M.; Manser, M.; and Young, A. (editors) Price Measurements and Their Uses, Chicago: University of Chicago Press.

5. $\quad$ Brandenburger, A.M. and B.J. Nalebuff (1997) Co-opetition, NY: Doubleday.

6. Bulkeley, William M. (1990). Software Users Are Beginning to Rebel Against the Steady Stream of Upgrades. 9/20/1990. The Wall Street Journal.

7. Bulow, J. I. Durable-Goods Monopolists. Journal of Political Economy, 90, (1982), 314-332.

8. Cowling, K., and J. Cubbin (1971) Price, quality and advertising competition: an econometric investigation of the United Kingdom car market. Economica, vol. 38, no. 152, pp. 378-394.

9. Chakravarti, A. and C. Janiszewski (2004) The Influence of Generic Advertising on Brand Preferences. Journal of Consumer Research, vol. 30 (March), pp. 487-502.

10. Chow, G. (1967) Technological change and the demand for computers. American Economic Review, vol. 57, pp. 1117-1130.

11. Cubbin, J. (1975) Quality change and pricing behaviour in the United Kingdom car industry 1956-1968. Economica, vol. 142, no. 65, pp. 43-58.

12. Dutta, A. (2001) Telecommunications and economic activity: An analysis of Granger causality. Journal of Management Information Systems, vol. 17, no. 4, pp. 71-96.

13. Engle, R.E. and C.W.J. Granger (1987), Cointegration and error-correction: representation, estimation and testing. Econometrica, vol. 55, pp. 251-276.

14. Fishman, A. and R. Rob (2002) Product Innovations and Quality-Adjusted Prices. Working paper, University of Pennsylvania.

15. Forker, O.D. and R.W. Ward (1993) Commodity Advertising: The Economics and Measurement of Generic Programs. New York, NY: Lexington Books.

16. Friedman, H.H. and L. Friedman (1976) Advertising Myopia. Journal of Advertising, vol. 5, pp. 29-31.

17. Fudenberg, D. and Tirole, J. Upgrades, trade-ins, and buybacks. The Rand Journal of Economics, 29, 2(1998), 235-258.

18. Gandal, N. (1994) Hedonic price indexes for spreadsheets and an empirical test for network externalities, The Rand Journal of Economics, vol. 25, pp. 160-170.

19. Gordon, R. (1990) The Measurement of Durable Good Prices. Chicago: University of Chicago Press.

20. Granger, C.W.J. (1996) Developments in the study of cointegrated economic variables. Oxford Bulletin of Economics and Statistics, vol. 48, pp. 213-227. 
21. Greenstein, S.H. (1994) Did computer technology diffuse quickly? Best and average practice in mainframe computers, 1968 - 1983. NBER working paper \#4647.

22. Hackett, G. (1990) Investments in technology-The service sector sinkhole? Sloan Management Review, Winter, pp. 97-103.

23. Hagerty, M.R. (1978). Model testing techniques and price-quality tradeoffs. Journal of Consumer Research, vol. 5, pp. 194-205.

24. Hoffman, D.L., and R.H. Rasche (1996), Assessing forecast performance in a cointegrated system. Journal of Applied Econometrics, vol. 11, no. 5, pp. 495-517.

25. Hold, D. and R. Perman (1994) Unit Roots and Cointegration for the Economist. Cointegration for the Applied Economist. (Edited by B.Bhaskara Rao). St.Martin's Press. New York.

26. Hui, Kai-Lung (2004) Product Variety Under Brand Influence: An Empirical Investigation of Personal Computer Demand. Management Science, Vol.50, No.5, pp. 686-700.

27. Johansen, S., and Juselius, K. Maximum likelihood estimation and inference on cointegration with application to the demand for money. Oxford Bulletin of Economics and Statistics, 52 (1990), 169-210.

28. Kennedy, P. (1998) A Guide To Econometrics. Fourth Edition. The MIT Press.

29. Klonaris, S. and D. Hallam. 2003. Conditional and Unconditional Food Demand Elasticities in a Dynamic Multistage Demand System. Applied Economics 35, 503-514.

30. Krantz, D.H.; Luce, D.R.; Patrick Suppes, P.; and Tversky, A. (1971). Foundations of Measurement. New York: Academic Press, 1971.

31. Krishnamurthy, S. (2000) Enlarging the Pie vs. Increasing One's Slice: An Analysis of the Relationship between Generic and Brand Advertising. Marketing Letters, vol. 11, pp. 37 - 48.

32. Krishnamurthy, S. (2001) The Effects of Provision Points on Generic Advertising Funding. Marketing Letters, vol. 12, pp. 315-325.

33. LeSage, J.P. (1990) A Comparison of the forecasting ability of ECM and VAR models. The Review of Economics and Statistics, vol. 72, no. 4, pp. 664-671.

34. Levin, I.P. and R.D. Johnson (1984) Estimating price-quality tradeoffs using comparative judgments. Journal of Consumer Research, vol. 11, no. 1, pp. 593-600.

35. Lin, J.L. and R.S. Tsay (1996), Co-integration constraint and forecasting: an empirical examination. Journal of Applied Econometrics, vol. 11, no. 5, pp. 519-538.

36. Maysami, R.C. and T.S. Koh (2000) Vector error correction model of the Singapore stock market. International Review of Economics \& Finance, vol. 9, no. 1, pp. 79-96.

37. McKenzie, M.D. and R.D. Brooks (1999) Research Design Issues in Time-Series Modeling of Financial Market Volatility. The McGraw-Hill Companies, Inc.

38. Ng, Cleste See Pui (2001). A decision framework for enterprise resource planning maintenance and upgrade: a client perspective. Journal of Software Maintenance and Evolution: Research and Practice. 13, (2001), 431-468.

39. Panko, R. (1991) Is office productivity stagnant? MIS Quarterly, vol. 15, no. 2, pp. 191-203.

40. Reeve, C.A. and D.A. Bednar (1994) Defining quality: alternatives and implications. The Academy of Management Review, vol. 19, no. 3, pp. 419-445.

41. Roach, S. (1987) America's technology dilemma: A profile of the information economy. Special Economic Study, Morgan Stanley.

42. Roach, S. (1991), Services under siege-The restructuring imperative. Harvard Business Review, vol. 69, no. 5, pp. 82-91.

43. Silberberg, E. 2000. The Structure of Economics: A Mathematical Analysis. The $3^{\text {rd }}$ Edition. McGraw-Hill, Inc.

44. Stevenson, W.J. (2002) Operations Management. The McGraw-Hill Companies, Inc.

45. Strassman, P. (1990) The Business Value of Computers. New Canaan, CT: Information Economics Press.

46. Varian, H.R. (1992) Microeconomic Analysis. Third Edition. W.W. Norton \& Company.

47. Varian, H.R. (1997) Versioning information goods working paper, University of California, Berkeley. http://www.sims.berkeley.edu/ hal/

48. Wang, C.H., R.D. Gopal, Y.A. Tung (1997) Diffusion of ladder-type innovations: a study of computer and communications convergence. Computers and Industrial Engineering, vol. 32, no. 3, pp. 497-507. 
49. Williams, G.W. (1999) Commodity Checkoff Programs as Alternative Producer Investment Opportunities: The Case of Soybeans. Agribusiness: An International Journal, vol. 15, no. 4, 539-552.

50. Wolinsky, A. (1983) Prices as Signals of Product Quality. Review of Economic Studies, vol. 50, no. 4, pp. 647-658.

\section{NOTES}

